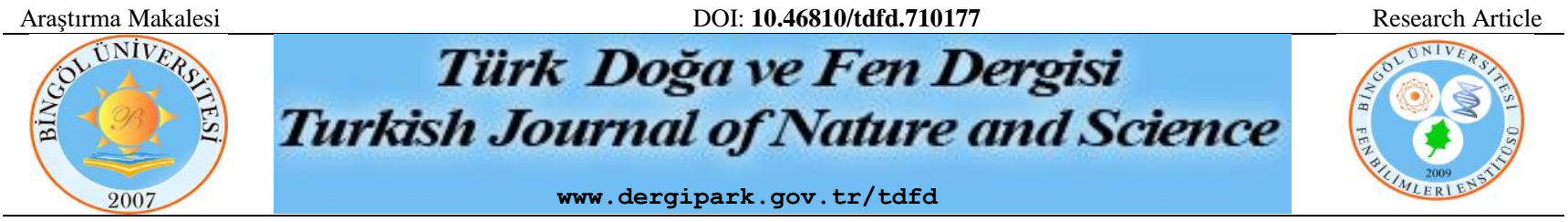

\title{
Elazı̆̆ Karakoçan Yöresi Buzağı ve Danalarında Eimeria Türlerinin Yaygınlığı
}

\author{
Yunus ESEN ${ }^{1 *}$, Ahmet BOZDAĞ $\breve{G}^{2}$ \\ ${ }^{1}$ Bingöl Üniversitesi, Solhan Sağlık Hizmetleri MYO, Tıbbi Laboratuvar Teknikleri Bölümü, Bingöl, Türkiye. \\ ${ }^{2}$ Karakoçan Mesleki ve Teknik Anadolu Lisesi, Elazı̆̆ Türkiye \\ Yunus ESEN ORCID No: 0000-0002-6231-1467 \\ Ahmet BOZDAĞ ORCID No: 0000-0002-2995-4137 \\ *Sorumlu yazar: yesen@bingol.edu.tr
}

(Alınış: 27.03.2020, Kabul: 19.05.2020, Online Yayınlanma: 18.06.2020)

\begin{abstract}
Anahtar
Kelimeler

Karakoçan,

Buzağı,

Eimeria,

Yaygınlık

Öz: Bu çalışmada, Elazı̆̆ Karakoçan ilçesi ve ilçeye bağlı köylerinde yaşayan buzağı ve danalarda Coccidiosis hastalığına sebep olan Eimeria türleri ve bu türlerin yaygınlığı tespit edilmiştir. Karakoçan yöresinde İlçe Merkezi, Sarıcan Beldesi, Başyurt, Bulgurcuk, Kalecik, Demirdelen ve Yenikaya köyleri olmak üzere toplam 7 farklı bölgeden materyal toplanmıştır. Bu süre içerisinde 112 aylık 119 tane buzağı ve dananın dışkı numunesi alınmıştır. Mikroskobik incelemeler neticesinde bu dışkı numunelerinin $60(\% 50,42)$ tanesinde Eimeria spp. ookistleri tespit edilmiştir. Ookist bulunduran dışkı örneklerine $\% 2,5$ potasyum dikromat $\left(\mathrm{K}_{2} \mathrm{Cr}_{2} \mathrm{O}_{7}\right)$ ilave edilmiş ve örneklerin sporlanmasından sonra tür tayinleri yapılmıştır. İncelemeler sonucunda dana ve buzağıların; Eimeria bovis (\%45), E. ellipsoidalis (\%30), E. auburnensis $(\% 28,3)$, E. alabamensis $(\% 26,6)$, E. zuerni (\%25), E. clindirica $(\% 13,3)$ olmak üzere toplam 6 tür tarafindan enfekte olduğu görülmüştür. Enfekte hayvanların 37'sinde $(\% 61,6)$ tek tür enfeksiyon tablosu mevcutken, 23 'ünde $(\% 38,4)$ miks enfeksiyon belirlenmiştir. En fazla yaygınlık 6-12 aylık yaşları arasında, simental ırkında, Yenikaya ve Demirdelen köyleri civarındaki hayvanlarda görülmüştür. Dişilerin \%58,8 (40 birey) ve erkeklerin \%39,2 (20 birey) enfekte olduğu tespit edilmiştir.
\end{abstract}

\section{The Prevalence of Eimeria Species in Calves in Elazığ Karakoçan Region}

Keywords

Karakoçan

district,

Calves,

Eimeria,

Prevalence

\begin{abstract}
In this study, Eimeria species that are causing coccidiosis disease and their prevalence were determined in Karakoçan district (Elazı̆̆ Province) and its villages. The materials were taken from different regions: Karakoçan center, Sarıcan Town, Başyurt, Bulgurcuk, Kalecik, Demirdelen, and Yenikaya villages. Within this period, the feces samples were taken from 119 calves aged between 1-12 months. Microscopic examination was resulted as $60(50.42 \%)$ of the samples were infected with Eimeria spp. oocysts. The feces samples containing oocysts were blended solution of $2.5 \%$ potassium dichromate $\left(\mathrm{K}_{2} \mathrm{Cr}_{2} \mathrm{O}_{7}\right)$ in the petri dishes and the species identification was performed after the sporulation. Results of examinations, the calves were infected with a total of six species i.e. E. bovis (45\%), E. ellipsoidalis (30\%) E. auburnensis (28.3\%) E. alabamensis (26.6\%), E. zuerni $(25 \%)$, E. clindirica (13.3\%). The pure and mix infection rates were $61.6 \%$ and $38.4 \%$, respectively. The most prevalence has been seen in the animals that are at 6-12 month-old, Simmental race, and around Yenikaya and Demirdelen villages. It has been determined that female $58.8 \%$ (40 individuals) and male 39.2\% (20 individuals) are infected.
\end{abstract}

sporozoit ve merozoit olmak üzere üç hayat evresine

\section{GİRIŞ}

Eimeria, kanatlı hayvanlar başta olmak üzere, sığır, keçi, koyun, tavşan gibi birçok hayvan türünde görülen, Apicomplexa şubesinde yer alan bir protozoa cinsidir. Hayat döngüsü bir konakta geçen bu parazitin hücresel özellikleri konağa yerleşmesine olanak sağlar. Ookist, sahiptir. Çeşitli hayat devirlerinde hem eşeyli, hem de eşeysiz üreme geçirirler. Eimeria ile enfekte olmuş hayvanlarda ishal, yorgunluk ve iştahsızlık şeklinde kendini gösteren coccidiosis hastalığı görülür. Coccidiosis hayvanların enfekte olmuş besinleri yemesi veya dışkı ile teması sonucu yayılır. Sonuçta kümes hayvanları ve memeli hayvan yetiştiriciliğinde her sene 
büyük miktarlarda maddi kayıplara neden olmaktadır [1].

Sığırlarda Eimariidae ailesine bağlı Eimeria ve Isospora cinslerine ait türler coccidiosise sebep olur. Eimeria ve Isospora türleri, tüm evcil ve yabani hayvanlarda görülen, özellikle dana ve buzağı gibi hayvanlarda hemorojik diyare, depresyon, zayıflama, kilo azalması ve bazen de ölüme sebep olabilir [2,3].

Sığırlarda cocciodiosis, tüm yaş gruplarında görülmekle beraber buzağılarda (0-6 ay) ve danalarda (6-12 ay) klinik olarak daha önemlidir. Eimeria türleri genellikle 3 haftalıktan 6 aylığa kadar olan buzağılarda ciddi enfeksiyonlara yol açmaktadır. Sı ğırlarda coccidiosise sebep olan türlerden en patojen olanları $E$. zuernii ve $E$. bovis'tir. $\mathrm{Bu}$ türler özellikle buzağılarda hemorojik diyareye sebep olurlar [2].

Dünyanın çeşitli ülkelerinde coccidiosisin yayılışı ile ilgili bilimsel araştırmalar yapılmıştır [2,4-9]. Yapılan bu araştırmalar sonucu dünyada 17 Eimeria ve 2 Isospora türünün sığır coccidiosisine neden olduğu, 11 Eimeria ve 1 Isospora türünün ise ülkemizde sığır coccidiosisine neden olduğu bildirilmiştir [6-10].

$\mathrm{Bu}$ çalışmada Doğu Anadolu'nun önemli hayvancılık merkezlerinden biri olan Elazığ Karakoçan yöresi buzağ1 ve danalarında Eimeria türlerinin yaygınlığının saptanması hedeflenmiştir. $\mathrm{Bu}$ çalışmayla Eimeria türlerinin neden olabileceği hastalıklar, korunma yolları ve parazit faunasının tespitine destek olmak amaçlanmıştır.

\section{MATERYAL VE METOT}

Bu çalışma kapsamında Elazığ Karakoçan ilçe Merkezi, Sarıcan Beldesi, Başyurt, Bulgurcuk, Kalecik, Demirdelen, Yenikaya köyleri (Şekil 1) olmak üzere toplam 7 yerleşim yerinden 119 buzağı ve danadan alınan dışkı numuneleri alınmıştır. Materyal toplanacak köyler, Elazığ Karakoçan ilçesinin geneli hakkında bilgi sahibi olmayı sağlayacak şekilde belirlenmiştir.

Karakoçan ilçe merkezi ve belirlenen köylere gidilerek buzağı ve danalardan rastgele dişkı örnekleri toplanmıştır (Tablo 1). Dışk1 örnekleri ayrı ayrı kaplara konarak numunesi alınan hayvana ait bilgiler kayıt altına alınmıştır. Numuneler en kısa süre içerisinde Bingöl Üniversitesi Biyoloji Araştırma Laboratuvarı'na getirilmiş ve inceleninceye kadar $+4{ }^{\circ} \mathrm{C}$ 'de saklanmıștır.

Karakoçan ilçe merkezi ve köylerden toplanan ve laboratuvarda $+4{ }^{\circ} \mathrm{C}$ 'de muhafaza edilen dıșkı örnekleri, doymuş tuzlu su santrifüj flotasyon yöntemi kullanılarak muayene edilmiştir [1,11]. Eimeria ookistlerinin görüldüğü numuneler ayrılarak daha sonra ookistlerin sporlandırılması amacıyla saklanmıștır. Eimeria ookistleri bakımından pozitif numunelerden yeterli miktarda alınıp her biri farklı kap içerisinde \%2,5'lik potasyum dikromat $\left(\mathrm{K}_{2} \mathrm{Cr}_{2} \mathrm{O}_{7}\right)$ karıştırılıp bu karışımlar hazır halde bekletilen petri kaplarına konularak oda ısısında beklemeye alınmışlardır. Sporlanmanın rahat gerçekleşmesi için gündüzleri iki saatte bir mevcut petri kaplarındaki karışım sporlanmada gerekli olan oksijen için ayrı bir baget yardımı ile karıştırılmıştır. Sporlanmadan sonra numuneler doymuş tuzlu su santrifüj flotasyon yöntemi ile incelenip ilgili literatürler $[1,7,9,12]$ eşliğinde, sporlanan ookistlerin morfolojik özelliklerinden yararlanarak tür tayinleri yapılmıştır. Çalışma sonuçlarının istatistik verilerine ait analizler kikare $\left(\mathrm{X}^{2}\right)$ testi kullanılarak yapılmıştır.

Tablo 1. Karakoçan'da dışkı bakısı yapılan dana ve buzağıların yerleşim merkezi, yaş, cinsiyet ve ırklarına göre dağılımı

\begin{tabular}{|c|c|c|c|c|c|c|c|c|c|c|c|c|c|c|}
\hline \multirow{3}{*}{ Yerleşim Merkezi } & \multicolumn{4}{|c|}{ Irk-Cinsiyet } & \multicolumn{8}{|c|}{ Yaş-Cinsiyet } & \multicolumn{2}{|c|}{ Toplam } \\
\hline & \multicolumn{2}{|c|}{ Simental } & \multicolumn{2}{|c|}{ Montofon } & \multicolumn{2}{|c|}{$0-1$ ay } & \multicolumn{2}{|c|}{$1-3$ ay } & \multicolumn{2}{|c|}{$3-6$ ay } & \multicolumn{2}{|c|}{$6-12$ ay } & & \\
\hline & q & $\hat{0}$ & q & $\hat{\sigma}$ & q & $\hat{0}$ & q & $\hat{0}$ & q & $\hat{0}$ & q & $\hat{0}$ & q & $\hat{\sigma}$ \\
\hline Merkez & 6 & 6 & 4 & 1 & - & - & 2 & 2 & 7 & 4 & 1 & 1 & 10 & 7 \\
\hline Sarıcan & 6 & 7 & 3 & 1 & - & 3 & 2 & 3 & 5 & 2 & 2 & - & 9 & 8 \\
\hline Başyurt & 7 & 8 & 1 & 1 & - & - & 4 & 4 & 4 & 4 & - & 1 & 8 & 9 \\
\hline Bulgurcuk & 5 & 4 & 5 & 3 & 1 & - & 5 & 1 & 3 & 4 & 1 & 2 & 10 & 7 \\
\hline Kalecik & 13 & 4 & - & - & - & - & 3 & 1 & 3 & 2 & 7 & 1 & 13 & 4 \\
\hline Demirdelen & 3 & 8 & 6 & - & - & - & - & 1 & 4 & 2 & 5 & 5 & 9 & 8 \\
\hline Yenikaya & 8 & 6 & 1 & 2 & - & 1 & - & - & 6 & 3 & 3 & 4 & 9 & 8 \\
\hline Toplam & 48 & 43 & 20 & 8 & 1 & 4 & 16 & 12 & 32 & 21 & 19 & 14 & 68 & 51 \\
\hline
\end{tabular}

\section{BULGULAR}

Karakoçan ve köylerinden dışkı numunesi toplanan 119 buzağı ve dananın incelemeler sonucunda 60'ında $(\% 50,42)$ altı farklı türe ait Eimeria spp. ookisti tespit edilmiştir. Eimeria türü tespit edilen buzağı ve danaların yerleşim yerlerine göre dağılımı Tablo 2'de gösterilmiştir. Numune alınan yerleşim merkezlerindeki Eimeria türlerinin yaygınlık değerleri \%41,18 ile \%58,82 arasında değişim gösterip, en yüksek yaygınlık Demirdelen ve Yenikaya köylerinde tespit edilmiştir.
Yerleşim merkezleri arasında yapılan karşılaştırmada görülen farklılıklar istatistiksel olarak önemsiz bulunmuştur $(\mathrm{P}>0,05)$.

Eimeria türlerinin cinsiyet, yaş ve ırka göre yayılış değerleri Tablo 3'te verilmiştir. Tabloda da görüldüğü gibi en yüksek yaygınlı 6-12 aylık yaş grubunda $(\% 60,6)$ görülmüss, ancak yaş seviyeleri bakımından farklılıklar istatistiksel olarak önemsiz bulunmuştur $(\mathrm{P}>0,05)$.

Irklar arasındaki en yüksek yaygınlık $(\% 51,6)$ simental 
1rk1 hayvanlarda tespit edilmiş, 1rklar arasında yapılan karşılaştırmada görülen farklılıklar istatistiksel olarak önemsiz bulunmuştur $(\mathrm{P}>0,05)$.

Cinsiyetlerine göre hayvanlar karşılaştırıldığında,

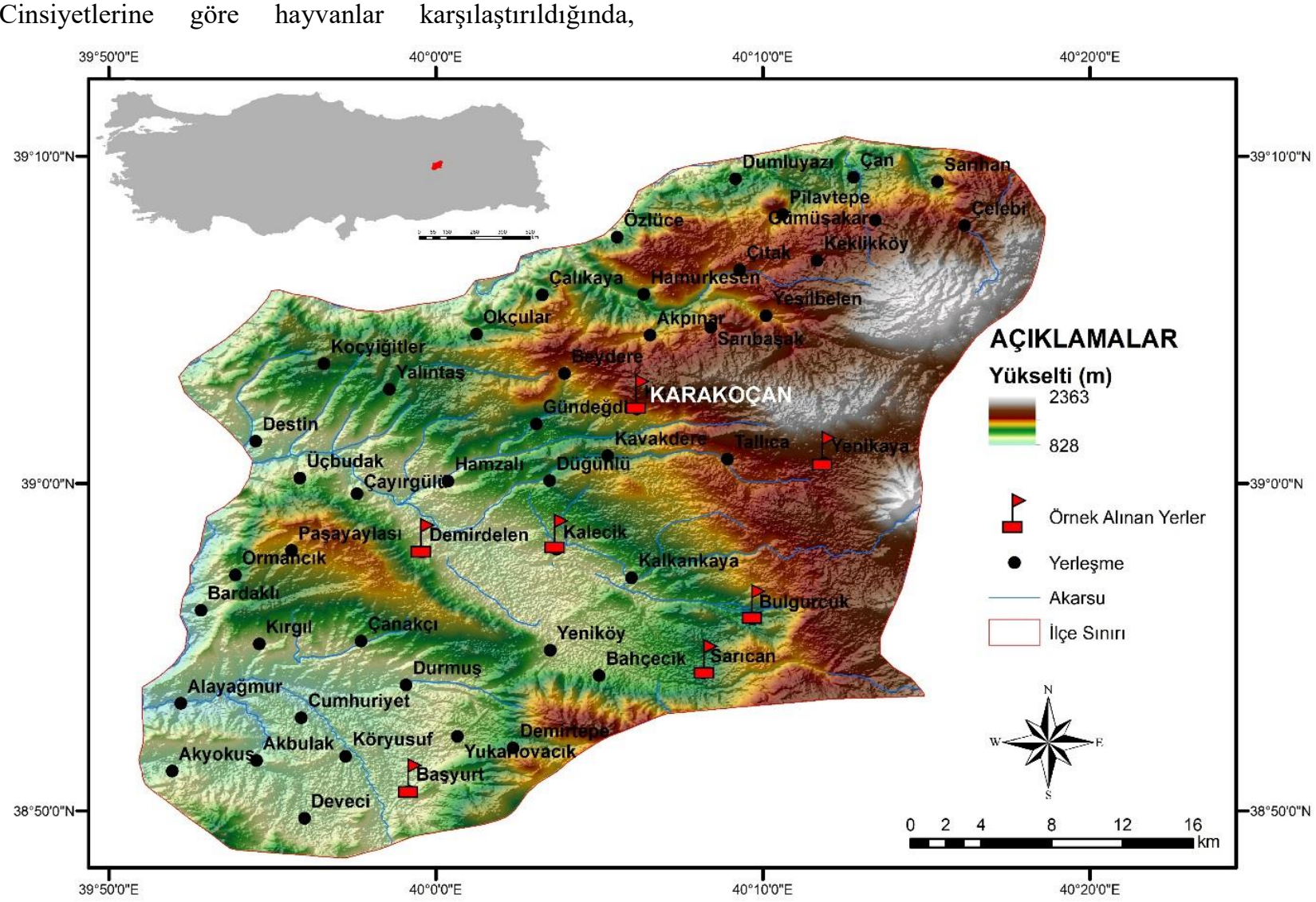

Şekil 1. Dışkı numunelerinin toplandığı yerler

Tablo 3. Elazığ Karakoçan yöresi buzağı ve danalarında Eimeria spp. ookistlerinin cinsiyet, yaş ve ırka göre yayılış değerleri

\begin{tabular}{|l|l|l|l|l|l|l|l|l|l|l|}
\hline \multirow{2}{*}{} & \multicolumn{2}{l}{ CINSIYET } & \multicolumn{2}{l}{ YAŞ } & \multicolumn{2}{l|}{ IRK } \\
\cline { 2 - 11 } & Dişi & Erkek & $\mathbf{0 - 1}$ & $\mathbf{1 - 3}$ & $\mathbf{3 - 6}$ & $\mathbf{6 - 1 2}$ & Simental & Montofon \\
\hline İncelenen hayvan sayısı (n) & 68 & 51 & 5 & 28 & 53 & 33 & 91 & 28 \\
\hline Enfekte bulunan hayvan sayısı (n) & 40 & 20 & 2 & 9 & 29 & 20 & 47 & 13 \\
\hline Enfekte bulunan hayvan oranı (\%) & 58,8 & 39,2 & 40 & 32,1 & 54,7 & 60,6 & 51,6 & 46,4 \\
\hline
\end{tabular}

Karakoçan yöresi buzağı ve danalarında tespit edilen Eimeria türlerinden en yaygın olanı E. bovis'tir ve toplamda $27(\% 45)$ hayvanda görülmüştür. En az yaygınlık gösteren tür ise 8 hayvanda bulunan $(\% 13,3)$ E. clindirica'dır.

Tablo 5'te görüldüğü gibi yerleşim yerlerinden toplanan dıșk1 numunelerinde, Eimeria ookistlerine rastlanan hayvanların 37 'sinin $(\% 61,6)$ tek tür, 13'ünün $(\% 21,6)$ iki tür, 5'inin $(\% 8,3)$ üç tür, 3'ünün $(\% 5)$ dört tür, 1'inin $(\% 1,6)$ beş tür, 1 'inin $(\% 1,6)$ altı tür ile enfekte olduğu belirlenmiștir. dișilerin $(\% 58,8)$ erkeklerden $(\% 39,2)$ daha yüksek bir enfeksiyon oranına sahip olduğu belirlenmiş ve bu farklılık istatistiksel olarak önemli bulunmuştur $(\mathrm{P}<0,01)$. Eimeria türleri ve enfeksiyon oranlan

\begin{tabular}{lcc}
\hline Eimeria türü & $\begin{array}{c}\text { Enfekte hayvan } \\
\text { sayısı(n) }\end{array}$ & Enfeksiyon oranı(\%) \\
\hline E. bovis & 27 & 45 \\
E. ellipsoidalis & 18 & 30 \\
E. auburnensis & 17 & 28,3 \\
E. alabamensis & 16 & 26,6 \\
E. zuernii & 15 & 25 \\
E. clindirica & 8 & 13,3 \\
\hline
\end{tabular}


Tablo 5. Bir veya birden fazla tür ile enfekte hayvan sayıları ve enfeksiyon oranları

\begin{tabular}{ccc}
\hline $\begin{array}{c}\text { Enfeksiyona sebep } \\
\text { olan Eimeria tür } \\
\text { sayısı (n) }\end{array}$ & $\begin{array}{c}\text { Enfekte hayvan } \\
\text { sayısı(n) }\end{array}$ & Enfeksiyon oranı(\%) \\
\hline $\mathbf{1}$ & 37 & 61,6 \\
$\mathbf{2}$ & 13 & 21,6 \\
$\mathbf{3}$ & 5 & 8,3 \\
$\mathbf{4}$ & 3 & 5 \\
$\mathbf{5}$ & 1 & 1,6 \\
$\mathbf{6}$ & 1 & 1,6 \\
\hline
\end{tabular}

İncelenen 119 hayvan içerisinde, normal görünümlü dışkıya sahip 106 hayvanın 51'inde $(\% 48,1)$, ishalli 13 hayvanın 9'unda $(\% 69,2)$ Eimeria spp. ookistleri tespit edilmiştir. Normal dışkıya sahip hayvanlar ile ishalli dışkıya sahip hayvanlar arasında yapılan karşılaştırmada ortaya çıkan farklılıklar istatistiksel olarak önemsiz bulunmuştur $(\mathrm{P}>0,05)$.

\section{SONUÇ}

Dünya genelindeki araştırma ve incelemeler neticesinde sığırlarda coccidiosise sebep olan 17 Eimeria ve 2 Isospora türü bulunmuştur. Bunların; E. zuernii, E. alabamensis, E. bukidnonensis, E. bovis, E. canadensis, E. ellipsoidalis, E. auburnensis, E. brasiliensis, E. mundaragi, E. illinoisensis, E. pellita, E. bombayansis, E. kosti, E. thianetti, E. cylindrica, E. subspherica, E. wyomingensis, Isospora aksaica ve Isospora sp. türleri olduğu tespit edilmiştir [9,13-18].

Türkiye'de ise; E. bovis, E. alabamensis, E. brasiliensis, E. bukidnonensis, E. auburnensis, E. canadensis, E. zuernii, E. ellipsoidalis, E. illinoisensis, E. subspherica, E. cylindrica olmak üzere 11 Eimeria türü ile 1 Isospora sp. türü kayıt altına alınmıştır [10,19-37]. Bu çalışmada ise Elazı̆̆ Karakoçan yöresinde; E. bovis, $E$. ellipsoidalis, E. auburnensis, E. alabamensis, E. zuernii ve E. clindirica olmak üzere 6 değişik Eimeria türü saptanmış, Isospora türüne rastlanmamıştır.

Türkiye'de sığır coccidiosisi ile ilgili daha önce yapılan çalışmalarda buzağı ve danalarda Eimeria türlerinin yaygınlığı \%0-93.3 arasında değişmektedir [10,20-37]. Bu çalışmalarda; Ankara'da \%16 [24], Elazı ̆̆'da \%44.6 ve \%51.4 [25,26], Samsun'da \%6.4 [27], Kars'da \%90.8 ve \%26.5 [22,28], Trakya bölgesinde \%68 [29], Konya'da \%23.8 [30], Van'da \%52.8, \%63.6 ve \%22.5 [20,31-3], Bursa'da \%49.3 [21], Hakkari'de \%89.1 [23], Afyon'da \%20 [34], Erzurum'da \%25.9 [35], Kırşehir'de $\% 50.6$ [10], Niğde'de \%10, Edirne'de \%0, Denizli'de $\% 60$, İstanbul'da \%40 ve Antalya'da \%0 [36] yaygınlık bildirilmiştir. Sayın [37] 15 farklı ilden topladığı dışkı örneklerindeki ookist yaygınlığını \%93.3 olarak bildirmiştir. Daha önceki çalışmaların bir kısmına [20,22,25,26,28,31-33] bakıldığında farklı zamanlarda aynı bölgede tespit edilen Eimeria türlerinin yaygınlık oranlarının da farklılık gösterebildiği anlaşılmaktadır. Kesik ve ark. [36] beş farklı ilde yaptıkları çalışmada Edirne ve Antalya'dan elde edilen dişkı örneklerinin hiçbirinde Eimeria ookistine rastlamamıştır. İyi bakım ve beslenme koşullarına rağmen coccidiosisin halen problem olduğu görülmektedir.
$\mathrm{Bu}$ çalışma sonucunda ortaya çıkan sonuçlar önceki çalışmalarla karşılaştırıldığında yaş gruplarına göre Eimeria türlerinin yaygınlığı benzerlik göstermektedir. $\mathrm{Bu}$ çalışmada 3-6 ay yaş grubundaki hayvanlarda yaygınlık daha fazla olup klinik açıdan ciddi enfeksiyonların en çok görüldüğü yaş aralığı olmasından dolayı bölgede hastalığın önlenmesi önem arzetmektedir. Daha önce yapılan çalışmalarda bölgeye göre dişi ve erkeklerde coccidiosis hastalığına yakalanma oranı farklılıklar gösterebilmektedir [10,20-26]. Bu çalışmada erkeklerde \%39,2, dişilerde \%58,8 Eimeria ookistleri görülmüştür. Cinsiyet oranları karşılaştırıldığında aralarındaki farklılıklar istatistiksel bakımdan önemli görülmüştür.

Ülkemizde sığır coccidiosisi ile ilgili yapılan araştırmalarda bir türle meydana gelen enfeksiyon oranının \%13,22-\%57,1 aralığında, birden fazla türle meydana gelen enfeksiyon oranının ise \%39-\%72,3 aralığında olduğu yapılan çalışmalar ile kayıt altına alınmıştır [10,11,21,22,25,26]. Bu çalışmada birden fazla tür ile meydana gelen enfeksiyon oran $\% 38,4$, tekli enfeksiyon oranı ise \%61,6 olarak kayıt altına alınmıştır.

Miks enfeksiyonlardaki tür sayısını Güleğen ve Okursoy [21] 2, Gül ve ark. [31] 4, Arslan ve Tüzer [11] 6, Sayın [37] 7, Arslan [22] en fazla 8 olarak saptamışlardır. Bu çalışmada miks enfeksiyonlarında en fazla 6 tür tespit edilmiştir.

$\mathrm{Bu}$ çalışma ile Elazı̆̆ Karakoçan yöresi buzağı ve danalarındaki Eimeria türleri tespit edilmiştir. Altı Eimeria türünün yaygınlığ $\% 50,42$ oranında saptanmış ve teşhis edilen türlerden sığırlarda en patojen tür olarak E. bovis (\%45) ve E. ellipsoidalis (\%30) belirlenmiştir. Yaygınlığın yüksek oranda görülmüş olması, coccidiosis ile mücadele metotlarının önemini bir kez daha göstermiştir. İlçe merkezi ve köylerde bulunan hayvanların beslenme ve barınma alt yapılarının iyileştirilmesi, rutin bakımlarının yapılması, yemlik ve sulukların temizliğine dikkat edilmesi coccidiosis hastalığının yayılmasını önlemede etkili olacağı önerilmektedir. Bununla birlikte 3-6 ay yaş grubundaki hayvanlarda ookist yaygınlığının yüksek olması önem verilmesi gereken hususlardan biri olarak görülmüştür. Karakoçan ilçesinde yapılan bu çalışmanın, bölgede hastalığın boyutlarının anlaşılmasında ve hastalıkla mücadelede katkı sağlayacağına inanmaktayız.

\section{Teşekkür}

$\mathrm{Bu}$ çalışma, Doç. Dr. Yunus ESEN danışmanlığında Ahmet BOZDAĞ'ın tamamlamış olduğu "Elazı̆̆ Karakoçan Yöresi Buzağı ve Danalarında Eimeria Türlerinin Yaygınlığı" isimli yüksek lisans tezinden üretilmiştir.

\section{KAYNAKLAR}

[1] Arslan MÖ. Siğır ve mandalarda coccidiosis. Türkiye Parazitol. Der. Yay. No: 17, İzmir; 2001. 
[2] Arslan MÖ, Sarı B. Eimeriidae (Memelilerde Coccidiosis). Veteriner Protozooloji, Medisan Yayınevi, Ankara; 2010.

[3] Gjerde B, Hele O. Effects of leucocyte extract, levamisole and sulphadimidine on natural coccidial infections (Eimeria spp.) in young lambs. Acta Vet. Scand. 1987;28(1):33-45.

[4] Ernst JV, Ciordia H, Stuedemann JA. Coccidia in cows and calves on pasture in North Georgia (U.S.A.). Vet. Parasitol. 1984;15:213-21.

[5] Oda K, Nishida Y (1990) Prevalence and distribution of bovine coccidia in Japan. Jap J Vet Sci. 1990;52(1):71-7.

[6] Davies SFM, Joyner LP, Kendal SB. Coccidiosis. 1th Edition, Oliver and Body LTD, Edinburgh, 1963.

[7] Pellerdy LP. Coccidia and Coccidiosis $2^{\text {nd }}$ Edition, Verlag Paul Parey, Berlin and Hamburg, 1974.

[8] Levine ND. Veterinary Protozoology, First ed. Iowa State Univ. Press Ames, Iowa, 1985.

[9] Levine ND, Ivens V. The Coccidian Parasites (Protozoa, Apicomplexa) of Artiodactyla. Illinois Bio. Monogr. 55, Illinois Univ. Pres, Urbana and Chicago, 1986.

[10] Güven E, Nalbantoğlu S, Orkun Ö, Akçay A, Koçak A (2010) Kırşehir ili Mucur yöresinde sığırlarda görülen Eimeria türlerinin yaygınlığı. Kafkas Üniv Vet Fak Derg. 2010;16(3):483-6.

[11] Arslan MÖ, Tüzer E. Prevalence of bovine eimeridosis in Thracia, Turkey. Turk J. Vet. Anim Sci., 1998;22:161-4.

[12] MAFF (Ministry of Agriculture, Fisheries and Food) Manual of Veterinary Parasitological Laboratory Techniques. References Book, London, 1986.

[13] McKenna PB. The identity and prevalence of coccidia species in sheep and cattle in New Zeland. Veterinary Journal. 1972;20(12):225-8.

[14] Prokopic J, Pavlasek I. Endoparasites of calves in large herds. Vet Med (Praha). 1977:22(8):505-12.

[15] Ernst JV, Ciordia H, Stuedeman JA. Coccidia in cows and calves on pasture in north Georgia (USA). Vet Parasitol. 1984;15(3-4):213-21.

[16] Ali SR, Latif BMA. Bovine coccidiosis in Baghdad area-Iraq. J Biol Sci Res. 1989;20(3):483-8.

[17] Chibunda RT, Muhairva AP, Kanbarage DM, Mtambo MM, Kusiluka LJ, Kazwala RR. Eimeriosis in dairy cattle farms in Morogoro municipaty of Tanzania. Prev Vet Med. 1997;31(34):191-7.

[18] Waruiru RM, Kyvsgaard NC, Thamsborg SM, Nansen P, Bogh HO, Munyva WK, Gathuma JM. The prevalence and intensity of helminth and coccidial infections in dairy cattle in central Kenya. Vet. Res. Commun. 2000;24(1):39-53.

[19] Özer E, Şaki CE. Türkiye'de Coccidiosis. In: Dinçer Ş. Editor. Coccidiosis, Türkiye Parazitoloji Derneği, Yayın no: 17; İzmir, 2001. p. 151-62.

[20] Değer S, Biçek K, Gül A, Eraslan E. Van yöresi buzağı ve danalarında Eimeria türlerinin yaygınlığı. Y.Y.Ü. Sağlık Bilimleri Dergisi. 2001;7(1-2):6972.
[21] Güleğen AE, Okursoy S. Bursa bölgesi sığırlarında coccidiosis etkenleri ve bunların yayılıșı. T Parazitol Derg. 2000;24(3):297-303.

[22] Arslan MÖ. Kars yöresi buzağılarında Eimeria türlerinin yaygınlığı. Kafkas Üniv Vet Fak Derg. 1997;3(2):141-9.

[23] Göz Y, Aydın A. Yüksekova (Hakkari) yöresi dana ve buzağılarında coccidiosis etkenlerinin yaygınlığı. Türkiye Parazitol Derg. 2005;29:13-6.

[24] Mimioğlu M, Göksu K, Sayın F. Ankara ve civarı sığırlarında coccidiosis olayları üzerine araştırmalar. Ankara Üniv Vet Fak Derg. 1956;3:136-58.

[25] Dumanlı N, Güler S, Erdoğmuş Z. Elazığ yöresinde sı̆̆ırlarda bulunan coccidia etkenleri ve bunların yayılışı. Doğa Türk Vet Hay Derg. 1993;17:223227.

[26] Yılmaz K, Özer E, Erkal N. Parazitsiz ve parazitli buzağılarda demir yetersizliği anemisi yönünden araştırmalar. F.Ü. Sağlık Bil. Derg. 1992;7:102111.

[27] Celep A, Açıcı M, Çetindağ M, Gürbüz İ. Samsun yöresi sığırlarında paraziter epidemiyolojik çalışmalar. Etlik Vet Mikrob Derg 1994; 7: 153 162.

[28] Çitil M, Arslan MÖ, Güneş V, Erdoğan HM. Neonatal buzağı ishallerinde Cryptosporidium ve Eimeria enfeksiyonlarının rolü. Kafkas Univ Vet Fak Derg 2004;10:59-64.

[29] Arslan MÖ, Erdoğan HM, Tanrıverdi S. Neonatal buzağılarda Cryptosporidiosis'in epidemiyolojisi. 13. Ulusal Parazitoloji Kongresi, 8-12 Eylül, Konya, 2003. s. 186.

[30] Aydenizöz M, Aldemir OS, Güçlü F. D1şkı muayenesiyle sığırlarda tespit edilen parazitler ve yayılışları. T Parazitol Derg 1999; 23: 83-88.

[31] Gül A, Biçek K, Değer S. Van Belediye mezbahasında kesimi yapılan sı ğırlarda bulunan Eimeria türleri ve bunların yayılış oranları. Y.Y.Üniv. Vet Fak. Derg. 2000;2(2):12-4.

[32] Gül A, Çiçek M, Kılınç Ö. Prevalence of Eimeria spp., Cryptosporidium spp. and Giardia spp. in calves in the Van province. Türkiye Parazitol Derg 2008;32:202-204.

[33] Göz Y, Altuğ N, Yüksek N, Özkan C. Parasites detected in neonatal and young calves with diarrhoea. Bull Vet Inst Pulawy 2006;50:345-348.

[34] Çiçek H, Sevimli F, Kozan E, Köse M, Eser M, Doğan N. Prevalence of coccidia in beef cattle in western Turkey. Parasitol Res. 2007;101:1239-43.

[35] Aktaş MS, Sarı B, Arslan MÖ. Erzurum ve çevresinde sütçü işletmelerdeki buzağılarda Eimeria türlerinin yaygınlığı. Kafkas Univ. Vet. Fak. Derg. 2008;14:25-9.

[36] Kesik HK, Kılınç ŞG, Şimşek S. Türkiye'nin Farklı İllerinden Elde Edilen Buzağı Dışkılarında Eimeria spp. Ookistlerinin Yaygınlığı ve Ookist Yükünün Belirlenmesi. F.Ü. Sağlık Bil. Vet. Derg. 2018;32(2):117-120.

[37] Sayin F. The species of Eimeria occurring in cattle in Turkey. Ankara Üniv. Vet. Fak. Derg. 1970;17:311-26. 